\title{
Risk Factors Associated with Major Complications after Ultrasound-Guided Percutaneous Renal Biopsy of Native Kidneys
}

\author{
Beatriz Pombas $^{a} \quad$ Eva Rodríguez $^{a} \quad$ Juan Sánchez $^{\mathrm{b}} \quad$ Aleksandar Radosevic $^{\mathrm{b}}$ \\ Javier Gimeno ${ }^{c}$ Marcos Busto $^{b}$ Clara Barrios $^{a}$ Laia Sans ${ }^{a}$ \\ Julio Pascuala María José Soler ${ }^{a}{ }^{\mathrm{d}}$ \\ a Department of Nephrology, Hospital del Mar, IMIM (Hospital del Mar Medical Research \\ Institute), Barcelona, Spain; ${ }^{b}$ Department of Radiology, Hospital del Mar, IMIM (Hospital \\ del Mar Medical Research Institute), Barcelona, Spain; ' Department of Pathology, Hospital \\ del Mar, IMIM (Hospital del Mar Medical Research Institute), Barcelona, Spain; dDepartment \\ of Nephrology, Hospital Universitari Vall d'Hebron, Vall d'Hebron Research Institute, \\ Universitat Autònoma de Barcelona, Barcelona, Spain
}

\section{Keywords}

Renal biopsy $\cdot$ Complications risk $\cdot$ Kidney disease $\cdot$ Bleeding

\begin{abstract}
Introduction: Percutaneous renal biopsy (PRB) of native kidneys is an important tool for diagnosis and management of renal disease. In this study, we analyzed the success, safety, and risk complications of PRB in our center. Methods: A retrospective review of ultrasound-guided PRB done at our institution from January 1998 to December 2017 was performed. Clinical and laboratory data were collected for 661 PRBs. Statistical analysis was performed using the Mann-Whitney $U$ test for continuous variable and chi-square test for categorical variables. Multivariate analysis using logistic regression was performed to assess factors associated with increased risk of complications after PRB. Results: The median age was 56 (42-68) years old, the majority were male (64\%) and white (82\%). Ten glomeruli were present in $63.5 \%$ of PRBs. Overall, the rate of complications was $16.6 \%$, where $15.1 \%$ of them were minor complications and $1.5 \%$ were major complications. Perinephritic hematoma accounted for the minor complication that occurred most frequently, whereas the need of a blood transfusion was the prevalent for major complications. By multivariate analysis, increased activated partial thromboplastin time (aPTT; OR 1.11,95\% Cl 1.035-1.180) and prebiopsy lower hemoglobin (Hgb; OR $1.61,95 \% \mathrm{Cl} 1.086-2.304$ ) were identified as independent risk factors for major complications. In addition, older patients (OR 1.057, 95\% Cl 1.001-1.117) were identified as an independent
\end{abstract}




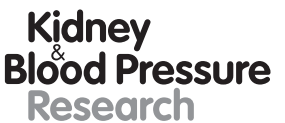

Research

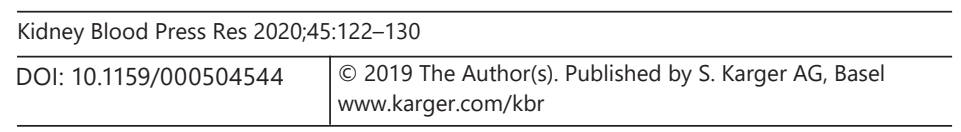

Pombas et al.: Complications after PRB

risk factor for blood transfusion requirement. Conclusion: The current risk of complications after native PRB is low. Major complications are most common in case of increased aPTT and decreased $\mathrm{Hgb}$ baseline level.

\section{Introduction}

Renal biopsy is a procedure that allows the diagnosis and prognosis of various diseases affecting native and transplanted kidneys. Iversen and Brun [1] were the first to perform native kidney biopsy in 1951, and the first published report regarding the use of kidney biopsy in the diagnosis of medical kidney disease was also in the 1950s [2]. Since its introduction, advancements have been made in biopsy technique leading to improve renal diagnosis while minimizing its complications [3].

The percutaneous renal biopsy (PRB) is the current standard of care, and the use of ultrasound-guided PRBs has allowed a decrease in the complications incidence [4]. PRBs are performed either by a nephrologist or a radiologist. PRBs are commonly performed under local anaesthesia with disposable, automatic, spring-loaded devices using 14-,16-, or 18-gauge needles (outer diameter of 2.11, 1.65, and $1.27 \mathrm{~mm}$, respectively). Some studies have shown that automated needles provide superior yield (more glomeruli) [5] and a decrease in major complication rates [6] when compared to hand-driven (Trucut) systems. PRBs are considered satisfactory for diagnosis if they contain at least 8 glomeruli [7].

In certain renal diseases, with similar clinical expression, such as IgA nephropathy and vasculitis, performing this procedure will properly classify the disease and subsequently treatment. In addition, it will help to predict the renal progression and response to treatment in each patient. Important to note that there are certain pathological entities such as lupus nephropathy, which treatment depends on renal histological classification [8].

Complications of renal biopsies have clearly decreased after the introduction of guided ultrasound PRB [4]. The severity of complications is categorized into major (need for an intervention such as blood transfusion or an invasive radiologic or surgical procedure, severe hypotension, acute renal obstruction, renal failure, septicemia, or death) and minor complications (severe flank pain, gross hematuria, and/or perinephric hematoma spontaneously resolving) [9]. European and American series have described minor complications in 10-20\% and major complications in 1.2-6.6\% of PRB patients [8]. In concordance with this, a Spanish study performed by Pendon-Ruiz de Mier et al. [10] described minor complications in 19.1\% and major complications in 3.7\%. Complications, specifically minor or major bleeding, have been associated with coagulation alterations, previous use of antiplatelet drugs, and a decrease in renal size [11-13].

In this study, we propose to evaluate the incidence of clinical complications after ultrasound-guided PRB performed by radiologist in our center. We also plan to study the risk factors for minor and major complications after PRB. This approach is aimed to detect patients at risk for minor and major complications before PRB procedure.

\section{Material and Methods}

A retrospective study of PRB in adult patients was conducted. The procedures were performed from January 1998 to December 2017, on native kidneys at the Radiology department of Hospital del Mar (Barcelona). In that period, all of the native kidney biopsies in our center were performed by radiologists. To avoid inclusion bias, all consecutive and/or 


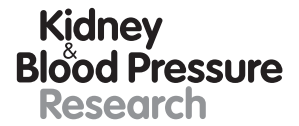

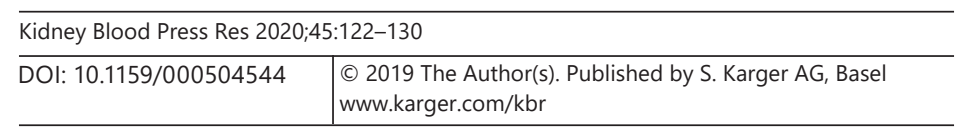

Pombas et al.: Complications after PRB

eligible patients in the specified period were included in the study. PRB guided by ultrasound was performed with automatic needles, of which the 16-gauge $(G)$ was the most commonly used. Usually, 2 or 3 passes were carried out in the lower left renal pole and with the patient in prone position. The study followed the ethical standards of the Institutional Committee on human experimentation and with the Helsinki Declaration of 1975, as revised in 2000 (CEIC $2018 / 7842 /$ I). Informed consent for renal biopsy was signed for each patient. Consent for this retrospective study was not needed.

Information collected at the time of PRB including: the date of the biopsy, age, gender, ethnic group, cause for renal biopsy, hypertension, diabetes mellitus, systolic and diastolic blood pressures (BPs), prothrombin time, activated partial thromboplastin time (aPTT), prebiopsy creatinine, prebiopsy hemoglobin ( $\mathrm{Hgb})$, platelet count, and antiplatelet drugs. It is worth of mention that prebiopsy desmopressin was not used.

PRB was performed after local anaesthesia in the lower pole in the left kidney. Following the procedure, patients laid in bed on their back for 4-6 $\mathrm{h}$ and then remained in the bed for 23-24 h on observation. Patients were monitored, and the following variables were studied: type of needle, needle passes, number of glomeruli, post biopsy Hgb, post biopsy creatinine, pain in the area of the puncture, minor complication, and major complication.

The inclusion criteria were the accomplishment of PRB and the presence of blood test before and after kidney biopsy. Exclusion criteria were defined as patients younger than 18 years old, renal biopsies performed by nephrologists, and the absence of analytical control pre or post renal biopsy.

The main variable of our study was the presence of post renal biopsy complication. The severity of PRB complications was categorized as minor, those resulting in decrease of $\mathrm{Hgb}$ $\geq 1 \mathrm{~g} / \mathrm{dL}$, hematoma, hematuria, or both, without the need for any type of intervention, or major, those resulting in an active bleeding and hematoma requiring blood transfusion, arteriovenous fistula, requiring surgery, nephrectomy, arteriography, embolization, or death.

Statistical analysis: We calculated that a random sample of 661 individuals will be enough to estimate, with a confidence of $95 \%$ and an accuracy of \pm 3 percentage units, with a percentage of approximately $19 \%$. Variables distribution was analyzed by the Kolmogorov-Smirnov test. Qualitative variables that followed a normal distribution were expressed by mean and SD. Nonparametric variables were expressed by median and interquartile range (25-75). Qualitative variables were expressed as a percentage. For comparison of 2 means, $t$ Student or Mann-Whitney U test was used according to the distribution of the variables. To study the relationship between 2 qualitative variables, the chi-square test was used. A one-way ANOVA test was used for multiple comparisons. Finally, multivariate binary logistic regression models were performed to assess factors associated with an increased risk of major complications or blood transfusion needed after renal biopsy. Variables with $p$ value $<0.05$ were retained in the final model and reported as OR with $95 \%$ CIs. A $p$ value of $<0.05$ was considered significant.

\section{Results}

\section{Demographic, Clinical, and Laboratory Characteristics}

PRB of native kidneys was performed in 661 adult patients with the use of real-time ultrasound in the radiology unit. The median age of the patients was 56 (42-68) years old, and the majority of them were male (64\%) and white (82\%; Table 1). Sixty-four percent of the patients had previous history of hypertension and $21 \%$ had previous history of diabetes. The median BP at the time of biopsy was 133/77 mm Hg (120-147/69-87 mm Hg), 31\% of patients had a systolic BP $>140$ and $>170 \mathrm{~mm} \mathrm{Hg}$ in $>4.7 \%$ of the cases. The median creatinine 


\section{Kidney \\ Blood Pressure \\ Research}

Table 1. Baseline characteristics

\begin{tabular}{l|l}
\hline Kidney Blood Press Res 2020;45:122-130 \\
\hline DOI: 10.1159/000504544 & $\begin{array}{l}\text { @ 2019 The Author(s). Published by S. Karger AG, Basel } \\
\text { www.karger.com/kbr }\end{array}$ \\
\hline
\end{tabular}

Pombas et al.: Complications after PRB

\begin{tabular}{lc}
\hline & All patients \\
\hline Patients, $n$ & 661 \\
Age, years, median (IQR) & $56(42.5$ to 68$)$ \\
Gender, male, $n$ (\%) & $425(64)$ \\
Ethnic group, \% & \\
$\quad$ Caucasian & 82 \\
$\quad$ Latin-American & 6 \\
$\quad$ Arabian & 6 \\
$\quad$ African/others & 6 \\
BP, median (IQR) & \\
$\quad$ Systolic, mm Hg & $133(120$ to 147$)$ \\
$\quad$ Diastolic, mm Hg & $77(69$ to 87$)$ \\
SCr, mg/dL, median (IQR) & $1.5(1.02$ to 2.52$)$ \\
$\quad>1.5$ mg/dL, \% & 62.7 \\
PT, \%, median (IQR) & $100(90$ to 111$)$ \\
aPTT, s, median (IQR) & $30.3(27.5$ to 33.2$)$ \\
Pre-Hgb, g/dL, median (IQR) & $12(10.2$ to 13.7$)$ \\
Post-Hgb, g/dL, median (IQR) & $11.8(10$ to 13.7$)$ \\
Change in Hgb, g/dL, median (IQR) & $0.1(-0.3$ to 0.6$)$ \\
\hline
\end{tabular}

BP, blood pressure; SCr, serum creatinine; PT, prothrombin time, aPTT, activated partial thromboplastin time; Pre-Hgb, pre-biopsy hemoglobin; Post-Hgb, post-biopsy hemoglobin.

was $1.5(1.02-2.52) \mathrm{mg} / \mathrm{dL}$, platelet count 237,000 (191,250-291,000) per microliter, prothrombin time was 99.7 (82.9-116.6) \%, and aPTT was 30.3 (27.5-33.2) s. At the time of biopsy, median value for $\mathrm{Hgb}$ was $12(10.2-13.7) \mathrm{g} / \mathrm{dL}$, which was $<11 \mathrm{~g} / \mathrm{dL}$ in $37 \%$ and $<10$ $\mathrm{g} / \mathrm{dL}$ in $23 \%$ of patients, and following PRB the Hgb decreased $0.1(-0.3$ to 0.6$) \mathrm{g} / \mathrm{dL}$.

\section{Adequacy and Indications for Kidney Biopsy}

Ninety-nine percent of the biopsies had glomeruli, 5 glomeruli were present in 85.6, and 10 glomeruli in $63.5 \%$ of biopsies. The number of glomeruli per biopsy was 13 (7-21). Sixtytwo percent of PRB were performed with a 16-gauge needle. The indications for PRB were nephrotic-range proteinuria in $27 \%$ of patients, chronic kidney disease with hematuria and/ or proteinuria in $23 \%$, non-nephrotic range proteinuria and/or hematuria $24 \%$, acute renal failure in $17 \%$, nephritic syndrome $6 \%$, and isolated hematuria $3 \%$.

\section{Biopsy Complications}

Complications following PRB were observed in 110 biopsies (16.6\%; Table 2). From those, $100(15.1 \%)$ were minor complications and $10(1.5 \%)$ were major complications. The most frequent minor complications were perinephric or small hematoma $(5.4 \%)$, followed by a drop in $\mathrm{Hgb}$ level of $>1 \mathrm{~g} / \mathrm{dL}$ (5.1\%). Major complications are depicted in Table 2. Blood transfusion was needed in a total of 8 PRBs. Patients with major complications had a larger aPTT $(41.3 \pm 22.2 \mathrm{~s}, p<0.001)$, as well as a low level of Hgb in the moment of the biopsy ( $9.8 \pm 1.5 \mathrm{~g} / \mathrm{dL}, p=0.007$; Fig. 1$)$, and lowest Hgb after the PRB (8.6 $\pm 1.4 \mathrm{~g}$ / $\mathrm{dL}, p<0.001$; Table 3). In addition, the indication of the PRB, specifically nephrotic-range proteinuria $(29 \%, p=0.026)$, was associated with minor complications as compared with patients without them. As expected, the patients with major and minor complications stayed more days at hospital as compared to the PRB patients without complications ( $p=$ 0.006). We were also able to identify that from all the patients who underwent PRB, 19 of them presented pain in the biopsy area. From those, 15 of them presented complications 
Kidney

Blood Pressure

Research

Table 2. Biopsy complications

\begin{tabular}{l|l}
\hline Kidney Blood Press Res 2020;45:122-130 \\
\hline DOI: 10.1159/000504544 & $\begin{array}{l}\text { @ 2019 The Author(s). Published by S. Karger AG, Basel } \\
\text { www.karger.com/kbr }\end{array}$ \\
\hline
\end{tabular}

Pombas et al.: Complications after PRB

\begin{tabular}{lc}
\hline & Patients, $n(\%)$ \\
\hline Patients & 661 \\
Minor complications & $100(15.1)$ \\
Hematuria & $17(2.57)$ \\
Perinephric hematoma spontaneous resolving & $36(5.44)$ \\
Hematuria and hematoma & $10(1.51)$ \\
Loss $>1$ point of hemoglobin & $34(5.13)$ \\
Loss =1 point of hemoglobin & $3(0.45)$ \\
Major complications & $10(1.5)$ \\
Severe hematoma & $2(0.3)$ \\
Active bleeding & $1(0.15)$ \\
Arteriovenous fistula & $1(0.15)$ \\
Hematoma & $6(0.9)$ \\
Nephrectomy & 0 \\
Death & 0 \\
\hline
\end{tabular}

Fig. 1. Pre-biopsy hemoglobin levels in patients without complications, with major complications, and with minor complications after renal biopsy in native kidneys.

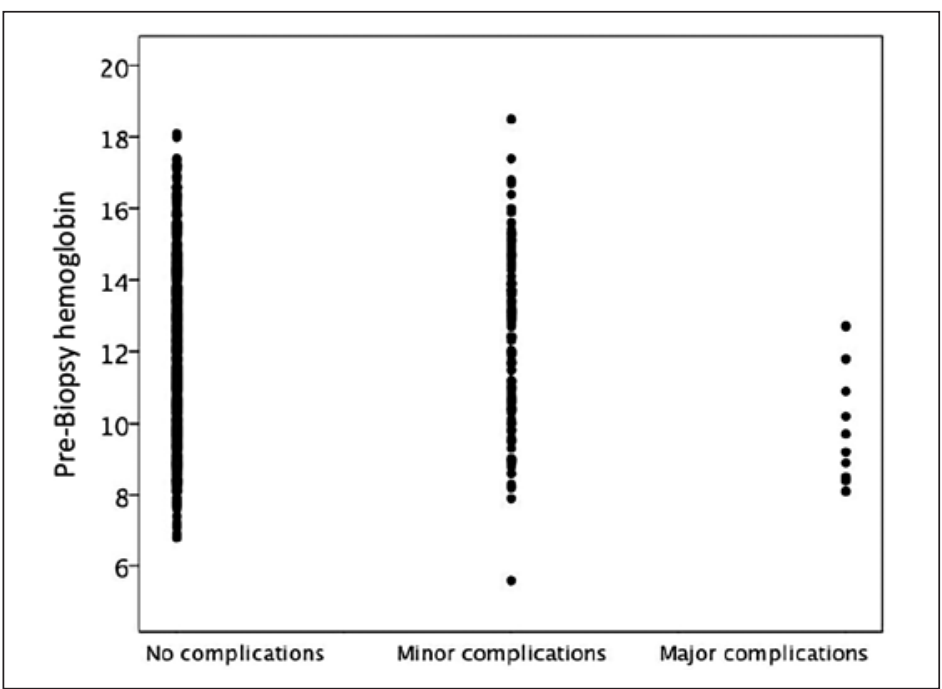

$(p<0.001)$, compared to the ones without complications. No deaths or nephrectomies were observed after PRB. No differences were found regarding platelet count and history of antiplatelet therapy (data not shown). No differences were found regarding the biopsy time period, first period from 1998 to 2007 years and second period from 2008 to 2017 (data not shown).

Multivariate analyses were performed to assess factors associated with an increased risk of major complications and the need of blood transfusion after renal biopsy. As shown in Table 4, an increased aPTT ( $p=0.003,95 \%$ CI 1.035-1.180) and a lower Hgb at the moment of PRB ( $p=0.017 ; 95 \%$ CI 1.086-2.304), mainly pre-biopsy Hgb $<10 \mathrm{~g} / \mathrm{dL}$ ( $p=0.018 ; 95 \%$ CI 01.356-27.725), were identified as risk factors for major complications after PRB. Thus, patients with increased aPTT were 1 time and patients with pre-biopsy $\mathrm{Hgb}<10 \mathrm{~g} / \mathrm{dL}$ were 6.13 times more likely to have a major complication. In addition, older patients were one time more likely to need a blood transfusion after PRB ( $p=0.046,95 \%$ CI 1.001-1.117). 
Table 3. Baseline characteristics based on complication status

\begin{tabular}{|c|c|c|c|c|}
\hline & $\begin{array}{l}\text { No } \\
\text { complication }\end{array}$ & $\begin{array}{l}\text { Minor } \\
\text { complication }\end{array}$ & $\begin{array}{l}\text { Major } \\
\text { complication }\end{array}$ & $p$ value \\
\hline Patients & 551 & 100 & 10 & \\
\hline Age, years, mean \pm SD & $54.9 \pm 16.3$ & $52.9 \pm 17.3$ & $58.3 \pm 16.2$ & 0.400 \\
\hline Gender, male, $\%$ & 65.2 & 60.6 & 60 & 0.656 \\
\hline Ethnic group, \% & & & & 0.543 \\
\hline Caucasian & 82.9 & 77.6 & 100 & \\
\hline Latin-American & 6.3 & 7.1 & 0 & \\
\hline Arabian & 5.4 & 7.1 & 0 & \\
\hline Others & 5.4 & 8.1 & 0 & \\
\hline \multicolumn{5}{|l|}{$\mathrm{BP}$, mean $\pm \mathrm{SD}$} \\
\hline Systolic, mm Hg & $134.0 \pm 21.9$ & $135.9 \pm 18.2$ & $142.3 \pm 16.4$ & 0.478 \\
\hline Diastolic, mm Hg & $76.8 \pm 13.5$ & $79 \pm 12.7$ & $81.0 \pm 13.0$ & 0.341 \\
\hline Creatinine, $\mathrm{mg} / \mathrm{dL}$, mean $\pm \mathrm{SD}$ & $2.2 \pm 3.9$ & $1.9 \pm 1.7$ & $3.8 \pm 2.4$ & $0.298^{\mathrm{b}}$ \\
\hline $\mathrm{PT}, \%$, mean $\pm \mathrm{SD}$ & $99.8 \pm 16.8$ & $99.4 \pm 16.7$ & $92 \pm 16.5$ & 0.338 \\
\hline aPTT(s), mean \pm SD & $30.7 \pm 5.2$ & $30.4 \pm 6.1$ & $41.3 \pm 22.2$ & $<0.001^{\mathrm{b}}$ \\
\hline Pre-Hgb, g/dL, mean \pm SD & $12.0 \pm 2.3$ & $12.3 \pm 2.4$ & $9.8 \pm 1.5$ & $\mathbf{0 . 0 0 7}{ }^{\mathrm{b}}$ \\
\hline Post-Hgb, g/dL, mean \pm SD & $12.1 \pm 2.3$ & $11.3 \pm 2.3$ & $8.6 \pm 1.4$ & $<0.001^{\text {a, b }}$ \\
\hline Change in Hgb, mean \pm SD & $+0.02 \pm 0.7$ & $-0.99 \pm 0.97$ & $-1.2 \pm 0.51$ & $<0.001^{\mathrm{a}, \mathrm{b}}$ \\
\hline
\end{tabular}

BP, blood pressure; PT, prothrombin time; aPTT, activated partial thromboplastin time; Pre-Hgb, prebiopsy hemoglobin; Post-Hgb, post-biopsy hemoglobin. Bold values indicate $p<0.05$.

a $p<0.05$ : no complications versus minor complications.
b $p<0.05$ : no complications versus major complications.

Table 4. Baseline features predictive of complication (A) or need for transfusion (B)

\begin{tabular}{llll}
\hline Major complication & OR & $95 \%$ CI & $p$ value \\
\hline Model 1 & & & \\
$\quad$ Age, years & 1.018 & $0.975-1.064$ & 0.442 \\
$\quad$ Pre-Hgb, g/dL & 1.613 & $1.086-2.304$ & $\mathbf{0 . 0 1 7}$ \\
$\quad$ aPTT & 1.11 & $1.035-1.180$ & $\mathbf{0 . 0 0 3}$ \\
$\quad$ Gender & 1.039 & $0.243-4.588$ & 0.959 \\
Model 2 & 1.019 & $0.974-1.067$ & 0.409 \\
$\quad$ Age, years & 6.13 & $1.356-27.725$ & $\mathbf{0 . 0 1 8}$ \\
$\quad$ Pre-Hgb <10 g/dL & 1.121 & $1.046-1.202$ & $\mathbf{0 . 0 0 1}$ \\
$\quad$ aPTT & 1.118 & $0.253-4.944$ & 0.883 \\
$\quad$ Gender & 1.057 & $1.001-1.117$ & $\mathbf{0 . 0 4 6}$ \\
Transfusion & 1.87 & $0.135-2.119$ & 0.374 \\
$\quad$ Age, years & 1.050 & $0.976-1.130$ & 0.001 \\
$\quad$ Gender & 5.6 & $1.287-23.969$ & $\mathbf{0 . 0 2 2}$ \\
$\quad$ aPTT & & & \\
$\quad$ Pre-Hgb $<10 \mathrm{~g} / \mathrm{dL}$ & &
\end{tabular}

Pre-Hgb, pre-biopsy hemoglobin; aPTT, activated partial thromboplastin time. Bold values indicate $p<0.05$.

\section{Discussion}

In this study, we reinforced the knowledge that PRB is a safe and successful procedure that allows us to establish the proper diagnosis and subsequently treatment in patients with kidney disease. In our hands, complications occurred in $16.6 \%$ of cases and major complications only in $1.5 \%$ of patients. Interestingly, we did not observe any nephrectomy or death after PRBs performed in these almost 20 years, at our center. 


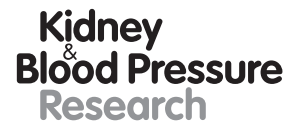

Kidney
Blood Pressure
Research \begin{tabular}{l|l}
\hline Kidney Blood Press Res 2020:45:122-130 \\
\hline DOI: 10.1159/000504544 & $\begin{array}{l}\text { @ 2019 The Author(s). Published by S. Karger AG, Basel } \\
\text { www.karger.com/kbr }\end{array}$ \\
\hline
\end{tabular}

Pombas et al.: Complications after PRB

Patients are increasingly demanding information about invasive procedures and the risks associated with them. Renal biopsies are performed more safely, compared to the past, the use of ultrasound guidance as well as smaller needles ensures fewer complications and more safety in clinical practice [14]. Currently, alternatives to an invasive procedure have been explored, but PRB ultrasound guided remains the golden standard approach [15]. In some cases, when PRB is contraindicated for high bleeding risk or one-kidney patient, transjugular renal biopsy can be performed [16]. To our knowledge, this is the first report that demonstrated that pre-biopsy Hgb level is associated with major complications and bleeding after renal biopsy; however, the mechanisms of this relation are unknown interestingly in other diseases such as acute myocardial infarction and atrial fibrillation $[17,18]$.

A recent study by Esposito et al. [19] observed major complications in 1.2\% of patients and minor complications in $17.3 \%$ after PRB ultrasound guided was performed by interventional nephrologists in a middle size hospital. Furthermore, Pendón-Ruiz de Mier et al. [10] reported minor complications in $19.1 \%$ and major complications in $3.7 \%$. In concordance with this study, we reported minor complications in 100 patients $(15.1 \%)$ and major complications in 10 patients $(1.5 \%)$ after PRBs performed by a radiologist. Our complication's rate is similar with other studies that showed $10-20 \%$ of minor complications and $2-8 \%$ of major complications $[20,21]$. As expected, the majority of complications in our study were minor and mainly related to the presence of perinephric hematomas (36\% of all minor complications), followed by a decrease in Hgb (34\%, without clinical repercussion) and gross hematuria $(17 \%)$. Its resolution did not require any intervention or blood transfusion. As previously reported, the minor complications were also associated with a slight decrease in Hgb without clinical significance $[14,22]$. Of mention that in our institution ultrasound was only performed when complications are suspected, thus the incidence of perirenal hematomas post-PRB might be underestimated.

The weakness of PRBs is the major complication that should be avoided for patient safety. Fortunately, this type of complication was only observed in $1.5 \%$ of our PRB patients. These results are consistent with previous studies from Feldmann et al. [23] that reported major complications occurred in $2.4 \%$ of the patients, and none of them needed surgical intervention or resulted in death. In other studies, the majority of patients who presented major complications required blood transfusion (from 4 to $8 \%$ of all major complications) [7, 24], whereas only a small minority needed arteriography or embolization for stopping active bleeding $[10,14]$. In our study, death was not observed in any of the PRBs patients. Interestingly, the mortality rate has been estimated at 1/1,000 [25].

In a cohort study by Manno et al. [12], female gender, older patients, as well as a larger value of aPTT were identified as risk factors for bleeding complications after PRBs. In concordance, Korbet et al. [14] also found female gender as a risk factor for complications after PRBs [26]. The increased risk of female gender was ascribed to their different body composition as compared to men, that is, the greater percentage of fat mass in women might increase the hematoma expansion in the perirenal fatty tissue [12]. A study from Lees et al. [27] also demonstrated that old age was associated with a higher risk of major bleeding complications. Kohli et al. [28] suggested that the increased risk for complications after PRB in older people may be related to the increased arterial stiffness. In agreement with these findings, we were also able to determine that old age increases the blood transfusion requirement after PRBs. We also found that increased aPTT is a risk factor for major complications after PRBs. Furthermore, Hgb lower than $10 \mathrm{~g} / \mathrm{dL}$ was identified as a risk factor for major complication after native renal biopsy. These results demonstrated that patients with increased aPTT and decreased $\mathrm{Hgb}$ are at risk for major complication after PRB. In those patients, another strategy such as transjugular renal biopsy should be at least considered [16]. Another study identified serum creatinine, bleeding diatheses, amyloidosis, and hypertension as risk factors for 
complications after PRBs [29]. Whittier et al. [26] were able to identify increased baseline creatinine as a risk factor for bleeding complications (5.9 times). Shidham et al. [30] demonstrated that a higher systolic BP (>160 mm Hg) was significantly associated with bleeding complications (10.7\%), as compared to the patients with systolic BP <160 mm Hg (5.3\%).

PRBs have been performed according to different indications for the diagnosis and management of kidney disease. PRBs allow the nephrologists to indicate the correct treatment for delaying kidney disease progression. In our study, nephrotic-range proteinuria was associated with increased risk for minor complication after PRBs; however, in a previous reported study with the Norwegian Kidney Biopsy Registry data, the association between the indication for renal biopsy and developing complications was not observed [31].

The main limitation of our study was the lack of information regarding some parameters such as body weight or BP after PRBs. This limitation may be ascribed to the long timeline of our study and the different registration system; the clinical history was not computerized in our center until 2009; therefore, the records for the early dates of the study were mainly recorded by hand writing and subsequently difficult to track down.

\section{Conclusions}

In conclusion, the risk of major bleeding following ultrasound-guided native PRBs performed by radiologist is low. Major complications are more common in patients with increased aPTT and lower Hgb level prior PRB. Our data support that PRBs is a safe procedure, but patient should be cautiously evaluated in order to decrease the risk/benefit equation in the context of PRB.

\section{Disclosure Statement}

M.J.S. has received consulting fees or speaking honoraria from Boehringer Ingelheim, Janssen, AstraZeneca, Novo Nordisk, Eli Lilly, abbvie, and Esteve. M.J.S. has received travel funding from Otsuka and Vifor.

\section{Funding Sources}

This work was made possible with funding from the projects ISCIII-FEDER: PI16/00617, PI17/00257, and ISCIII-RETICS REDinREN: RD16/0009.

\section{Author Contributions}

B.P., E.R., and M.J.S. designed the study. B.P., M.J.S., and J.P. supervised the study. B.P. recruited the participants. J.S., A.R., and M.B. performed the renal biopsies. B.P. and M.J.S. wrote early draft of the manuscript. B.P., M.J.S., and J.G. analyzed and interpreted the data. C.B. and L.S. set the clinical criteria of the study. All authors have read and approved and revised the final version of the manuscript. 


\section{Kidney \\ Blood Pressure \\ Research}

\begin{tabular}{l|l}
\hline Kidney Blood Press Res 2020:45:122-130 \\
\hline DOI: 10.1159/000504544 & $\begin{array}{l}\text { @ 2019 The Author(s). Published by S. Karger AG, Basel } \\
\text { www.karger.com/kbr }\end{array}$ \\
\hline
\end{tabular}

Pombas et al.: Complications after PRB

\section{References}

1 Iversen P, Brun C. Aspiration biopsy of the kidney. Am J Med. 1951 Sep;11(3):324-30.

2 Kark RM, Muehrcke RC. Biopsy of kidney in prone position. Lancet. 1954 May;266(6821):1047-9.

3 Hogan JJ, Mocanu M, Berns JS. The native kidney biopsy: update and evidence for best practice. Clin J Am Soc Nephrol. 2016 Feb;11(2):354-62.

4 Prasad N, Kumar S, Manjunath R, Bhadauria D, Kaul A, Sharma RK, et al. Real-time ultrasound-guided percutaneous renal biopsy with needle guide by nephrologists decreases post-biopsy complications. Clin Kidney J. 2015 Apr;8(2):151-6.

5 Burstein DM, Korbet SM, Schwartz MM. The use of the automatic core biopsy system in percutaneous renal biopsies: a comparative study. Am J Kidney Dis. 1993 Oct;22(4):545-52.

6 Doyle AJ, Gregory MC, Terreros DA. Percutaneous native renal biopsy: comparison of a 1.2-mm spring-driven system with a traditional 2-mm hand-driven system. Am J Kidney Dis. 1994 Apr;23(4):498-503.

7 Roth R, Parikh S, Makey D, Foster J, Rozenblit G, Satoskar A, et al. When size matters: diagnostic value of kidney biopsy according to the gauge of the biopsy needle. Am J Nephrol. 2013;37(3):249-54.

8 Fogo AB. Approach to renal biopsy. Am J Kidney Dis. 2003 Oct;42(4):826-36.

9 Korbet SM, Volpini KC, Whittier WL. Percutaneous renal biopsy of native kidneys: a single-center experience of 1,055 biopsies. Am J Nephrol. 2014;39(2):153-62.

10 Pendón-Ruiz de Mier MV, Espinosa-Hernández M, Rodelo-Haad C, Esquivias-de Motta E, Gómez-Carrasco J, Ortega $\mathrm{R}$, et al. Prospective study of the complications associated with percutaneous renal biopsy of native kidneys: experience in a centre. Nefrologia. 2014 May;34(3):383-7.

11 Eiro M, Katoh T, Watanabe T. Risk factors for bleeding complications in percutaneous renal biopsy. Clin Exp Nephrol. 2005 Mar;9(1):40-5.

12 Manno C, Strippoli GF, Arnesano L, Bonifati C, Campobasso N, Gesualdo L, et al. Predictors of bleeding complications in percutaneous ultrasound-guided renal biopsy. Kidney Int. 2004 Oct;66(4):1570-7.

13 Zhang WJ, Zhang ZL, Guo S, Yuan Y, Chang JJ, He Y. Renal Parenchymal Thickness as a Predictor of Post Percutaneous Kidney Biopsy Complication. Urol Int. 2019;102(4):421-6.

14 Korbet SM, Gashti CN, Evans JK, Whittier WL. Risk of percutaneous renal biopsy of native kidneys in the evaluation of acute kidney injury. Clin Kidney J. 2018 0ct;11(5):610-5.

15 McConnell JD, Sagalowsky AI, Lewis SE, Gailiunas P, Helderman JH, Dawidson I, et al. Prospective evaluation of renal allograft dysfunction with 99mtechnetium-diethylenetriaminepentaacetic acid renal scans. J Urol. 1984 May;131(5):875-9.

16 Rathod KR, Popat BA, Pandey A, Jamale TE, Hase NK, Deshmukh HL. Safety and effectiveness of transjugular renal biopsy: A single center study. Indian J Nephrol. 2017 Mar-Apr;27(2):118-23.

17 Westenbrink BD, Alings M, Granger CB, Alexander JH, Lopes RD, Hylek EM, et al. Anemia is associated with bleeding and mortality, but not stroke, in patients with atrial fibrillation: Insights from the Apixaban for Reduction in Stroke and Other Thromboembolic Events in Atrial Fibrillation (ARISTOTLE) trial. Am Heart J. 2017 Mar;185:140-9.

18 Dauerman HL, Lessard D, Yarzebski J, Gore JM, Goldberg RJ. Bleeding complications in patients with anemia and acute myocardial infarction. Am J Cardiol. 2005 Nov;96(10):1379-83.

19 Esposito V, Mazzon G, Baiardi P, Torreggiani M, Semeraro L, Catucci D, et al. Safety and adequacy of percutaneous kidney biopsy performed by nephrology trainees. BMC Nephrol. 2018 Jan;19(1):14.

20 Cui S, Heller HT, Waikar SS, McMahon GM. Needle Size and the Risk of Kidney Biopsy Bleeding Complications. Kidney Int Rep. 2016 Aug;1(4):324-6.

21 Trajceska L, Severova-Andreevska G, Dzekova-Vidimliski P, Nikolov I, Selim G, Spasovski G, et al. Complications and Risks of Percutaneous Renal Biopsy. Open Access Maced J Med Sci. 2019 Mar;7(6):992-5.

22 de Mier MV, Espinosa-Hernández M, Rodelo-Haad C, de Motta EE, Gómez-Carrasco J, Ortega R, et al. Estudio prospectivo de las complicaciones asociadas a la biopsia percutánea en riñón nativo: experiencia en un centro. Nefrologia. 2014;34(3):383-7.

23 Feldmann Y, Böer K, Wolf G, Busch M. Complications and monitoring of percutaneous renal biopsy - a retrospective study. Clin Nephrol. 2018 Apr;89(4):260-8.

24 Sethi I, Brier M, Dwyer A. Predicting post renal biopsy complications. Semin Dial. 2013 Sep-Oct;26(5):633-5.

25 Hernández FR. Biopsia renal. NefroPlus; 2009.

26 Whittier WL, Gashti C, Saltzberg S, Korbet S. Comparison of native and transplant kidney biopsies: diagnostic yield and complications. Clin Kidney J. 2018 Oct;11(5):616-22.

27 Lees JS, McQuarrie EP, Mordi N, Geddes CC, Fox JG, Mackinnon B. Risk factors for bleeding complications after nephrologist-performed native renal biopsy. Clin Kidney J. 2017 Aug;10(4):573-7.

28 Kohli HS, Jairam A, Bhat A, Sud K, Jha V, Gupta KL, et al. Safety of kidney biopsy in elderly: a prospective study. Int Urol Nephrol. 2006;38(3-4):815-20.

29 Corapi KM, Chen JL, Balk EM, Gordon CE. Bleeding complications of native kidney biopsy: a systematic review and meta-analysis. Am J Kidney Dis. 2012 Jul;60(1):62-73.

30 Shidham GB, Siddiqi N, Beres JA, Logan B, Nagaraja HN, Shidham SG, et al. Clinical risk factors associated with bleeding after native kidney biopsy. Nephrology (Carlton). 2005 Jun;10(3):305-10.

31 Whittier WL. Complications of the percutaneous kidney biopsy. Adv Chronic Kidney Dis. 2012 May;19(3): 179-87. 